\title{
Hybrid algorithm based on MBHS and PSO with Optimal Power Flow Problem for Non-Smooth Cost Functions
}

\author{
C.Shilaja
}

\begin{abstract}
Optimal Power Flow (OPF) is the primary apparatus in power framework administrators for both working and arranging stages. It is made to define a couple of expectations dependent on power organizing factors with a couple of confinements. This paper examines the likelihood that utilizations couple of currently developed progressive ways to deal with anticipating answers for OPF issues based on ruler butterfly agreement search (MBHS) calculation which uses Particle swam streamlining (PSO) for ideal settings of OPF issue control factors. The standard IEEE 30-bus with IEEE 57-bus test framework is assessed and examined by the presentation of the proposed methodologies with different useful destinations and furthermore, the correlation is made to this strategy. At long last, the acquired outcomes that are recovered from the connected reproduction accommodate the MBHS and PSO with effective answers for the issue in $\mathrm{OPF}$.
\end{abstract}

Keywords: Optimal power flow (OPF), MBHS, and PSO.

\section{INTRODUCTION}

$\mathrm{O}$

ver the previous decades, the OPF is engaged with a wide scope of concern and it is built up in a spot as the significant hardware for the ideal task and assessing the advanced power frameworks. The significant rationale of OPF is advancing particular utilitarian target like cost capacity of piecewise quadratic, cost of the fuel as far as worth point impact and the system lines stream are a portion of the state factors. In like manner, the OPF issue is set to be the basic device that permits electrical utilizations which describe verifying cost productive administrators with electric power framework [5, $6]$.

In ongoing investigations, a few enhancement methods dependent on the population are executed to beat complex issues which incorporate all the advancement issues in the territory of intensity frameworks, for example, ideal receptive power stream, OPF, distribution and monetary dispatch [15]. By and large, procuring close ideal or ideal answers for the given issue may require a few trails alongside right alterations with related parameters. Maybe a couple of the given strategies in population based technique like tabu

Revised Manuscript Received on December 05, 2019.

* Correspondence Author

C.Shilaja*, Department of Electrical and Electronics Engineering, Kalasalingam Academy of Research and Education, Anand Nagar, Krishnankoil, Tamilnadu, India. Email: shilaja.research@gmail.com
Inquiries [16], calculation in hereditary [17], extemporized hereditary calculation [18], swarm molecule [19], separated development [20], reproduction toughening [21] and programming in transformative strategies [22] are effectively demonstrated to take care of OPF issues. To furnish a progressively substantial network alongside instruments of reenactment which covers a different edge of intensity framework explores in the field control framework academician which has made amazing impacts. Power Systems Analysis Toolbox (PSAT) is presented and created lately [23-24]. It is utilized to improve the calculation in a hereditary framework to settle OPF. The given methodologies have been connected on IEEE 30 transport framework just as different zones like IEEE RTS 96 that applies on 73 transport and 120 branch framework [19]

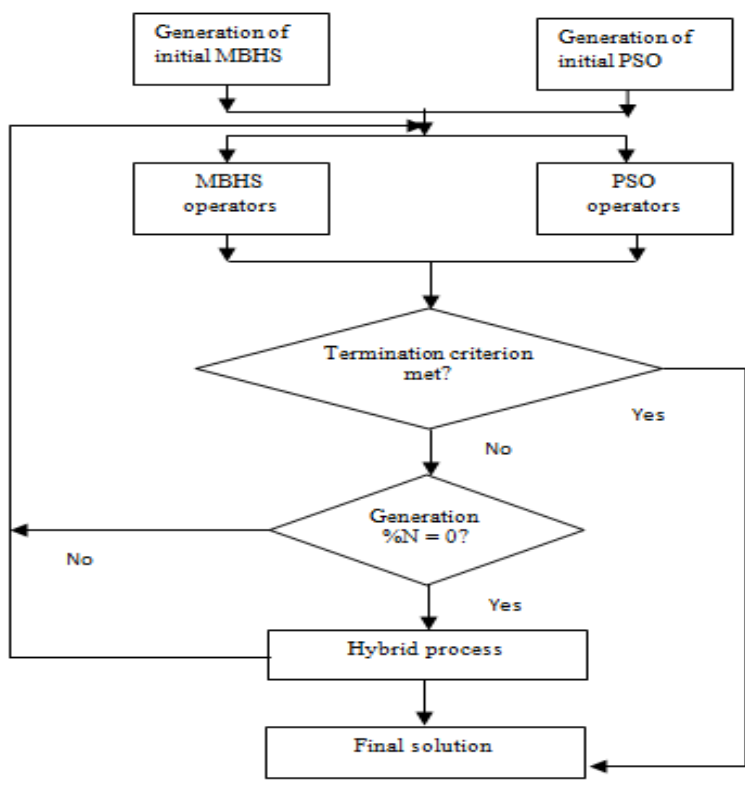

Fig. 1. Proposed model

\section{A. Proposed algorithm steps}

Step 0: Initialize both MBHS and PSO optimization

Step 1: Operators generation for both MBHS and PSO optimization

Step 2: Generate possible coefficient randomly, if Yes, then go to the final stage or if No, then go to the Step 1.

Step 3: Generation represents in $\%$ for $\mathrm{N}=0$, if Yes, then go to the hybrid process or if No, then it goes to the step 1 .

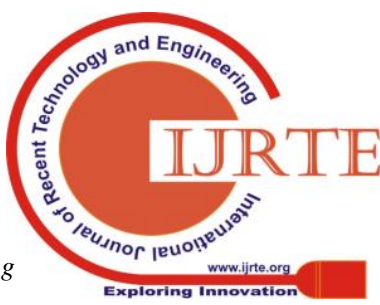


Step 4: Final (Accept) solution. Exist.

The remainder of this paper followed the sections, such as Section I describes the problem formulation, Section II elaborates the proposed methodology, Section III shows the evaluation of the proposed methodology with IEEE 30-bus and IEEE 57-bus. Finally, Section IV concludes the proposed methodologies.

\section{BACKGROUND WORK}

The customary OPF issue is changed to the meld contraptions in the structure of power [27-29]. In the progressing precedent, different streamlining computations, for instance, creamer GA [30], cross breed tabu interest and imitated treating (TS/SA) [27], certifiable coded GA [28], disparity headway $[28,29]$, have been proposed in the composition used for handling OPF issue of control structures equipped with contraptions FACTS. PSO calculation is with swarm learning framework subject to impersonating the sustenance looking for direct of feathered animals and has gotten extended thought in perspective on its peculiarity and looking limit. Use of PSO in the widened system is represented. Nevertheless, this system likewise has obstacles with May successfully for gotten close-by perfect in dealing with complex multimodal issues. Plus, it is slanted to encounter the evil impacts of the alleged "impact" ponders. Thus, the reliable accentuation is being given by the authorities' pool towards its further upgrade.

\section{FACTS WITH OPF OF PROBLEM FORMULATION}

In the power system, the satisfying of objective function for every inequality and equality constraints must reduce by OPF. The problem of OPF which can be formulated as [15]. Minimize $O F(p, q)$

Subject to,

$$
\begin{aligned}
& e(p, q)=0 \\
& i e_{1} \leq i e(p, q) \leq i e_{u}
\end{aligned}
$$

Where,

$O F(p, q)$ : function of objective

ie $(p, q)$ : inequality constraints set

$e(p, q)$ :equality constraints set

The constant factors are dynamic generator forces with the exception bus of slack, generators' discrete and voltages factors are transformers' tap site, responsive power infusions of shunt controllers and reactance estimations of TCSC gadgets with stage moving edges of TCPS gadgets.

$$
\begin{aligned}
& x=\left[P_{G 1}, V_{L 1, \ldots \ldots s} V_{L_{N L},} Q_{C_{1}, \ldots \ldots n} Q_{C_{N c^{s}}} S_{\mathbb{l}_{1}, \ldots x} S_{\mathbb{l}_{N n}}\right] \\
& y=\left[P_{G 2}, \ldots \ldots, P_{G_{N G}}, V_{G 1}, \ldots \ldots, V_{G_{N G}},\right. \\
& \left.T_{1}, \ldots \ldots . T_{N T}, Q_{C_{1}, \ldots \ldots \ldots}, Q_{C_{N c}}\right]
\end{aligned}
$$

\section{A. Types of Constraints}

In the next two sub-sections the constraints are mentioned with subject to OPF of TCPS and TCSC.

\section{Constraints of Equality}

The equation of load flow constraints are represented in (19) [20].

$$
\begin{aligned}
& \sum_{i=1}^{\mathrm{NB}}\left(P_{G i}-P_{L i}\right)+\sum_{i=1}^{\mathrm{NTCPS}} P_{i k}= \\
& \sum_{j=1}^{\mathrm{NB}} \sum_{j=1}^{\mathrm{NB}}\left|V_{i}\left\|V_{j}\right\| Y_{i j}\right| \cos \left(\theta_{i j}+\delta_{i}-\delta_{j}\right)
\end{aligned}
$$

$\sum_{i=1}^{N B}\left(Q_{G i}-Q_{L i}\right)+\sum_{i=1}^{N T C P S} Q_{i k}=$

$\sum_{j=1}^{W B} \sum_{j=1}^{M B}\left|V_{i}\left\|V_{j}\right\| Y_{i j}\right| \sin \left(\theta_{i j}+\delta_{i}-\delta_{j}\right)$

Where

\section{Constraints of Inequality}

i) Generator of constraints:

$$
\begin{aligned}
& V_{G \mathrm{i}} \min \leq V_{\mathrm{i}} \leq V_{G \mathrm{i}} \max \quad i=1,2, \ldots, N G \\
& P_{G i} \min \leq P \leq P_{G i} \max i=1,2, \ldots, N G \\
& Q_{\text {Gimin }} \leq Q_{i} \leq Q_{\text {Gi } \max } \quad i=1,2, \ldots, N G
\end{aligned}
$$

(ii) Constraints of load bus:

$$
V_{L i \min } \leq V_{i} \leq V_{L i \max } i=1,2, \ldots, N L
$$

i) Constraints Transmission line:

$$
S_{\mathbb{l}_{\mathrm{i}}} \leq S_{l_{\mathrm{i}} \max } i=1,2, \ldots, N T L
$$

ii) Constraints Transformer tap:

$$
T_{i \min } \leq T_{i} \leq T_{i \max } i=1,2, \ldots, N T
$$

iii) Constraints Shunt compensator:

$$
Q_{\text {ci min }} \leq Q_{\text {ci }} \leq Q_{\text {cimax }} i=1,2, \ldots, N T C S C
$$

iv) Constraints TCSC reactance:

\section{$1,2, \ldots, N T C S C$}

$$
X_{\text {ti } \min } \leq X_{\text {ci }} \leq X_{\text {ti } \max } i=
$$

(i) Constraints TCPS phase shift: TCPS phase shifts are constrained by their minimum and maximum limits as in (15)

$$
\emptyset_{i \min } \leq \emptyset_{c i} \leq \emptyset_{i \max } \quad i=1,2, \ldots, N T C P S
$$

\section{PROPOSED WORK}

\section{A. Monarch Butterfly Harmony Search (MBHS)}

In light of the extensive examination of congeniality search (HS) and ruler butterfly streamlining (MBO) figuring, the proposed creamer MBHS has been perceived in this fragment. The outcomes have uncovered that MBO can investigate the solicitation domain in all regards successfully and perceive the general immaculate inside a short extent of time; regardless, it mishandles the arrangement inappropriately in light of the way that routinely the upgrades of individual ruler butterflies are totally coordinated by Levy flight, which results in gigantic advances surveyed. Consequently, MBO may experience the abhorrent effects of ominous mixing in light of the manner in which that it might be stuck in some contiguous optima at early ages that can cause a low streamlining precision or even disappointment. Likewise, 
examination and abuse are two critical highlights in the game plan of a reasonable improvement check. In light of this standard, the congruity search for offers stunning similarity between the examination and misuse functionalities by tuning HMCR and PAR.

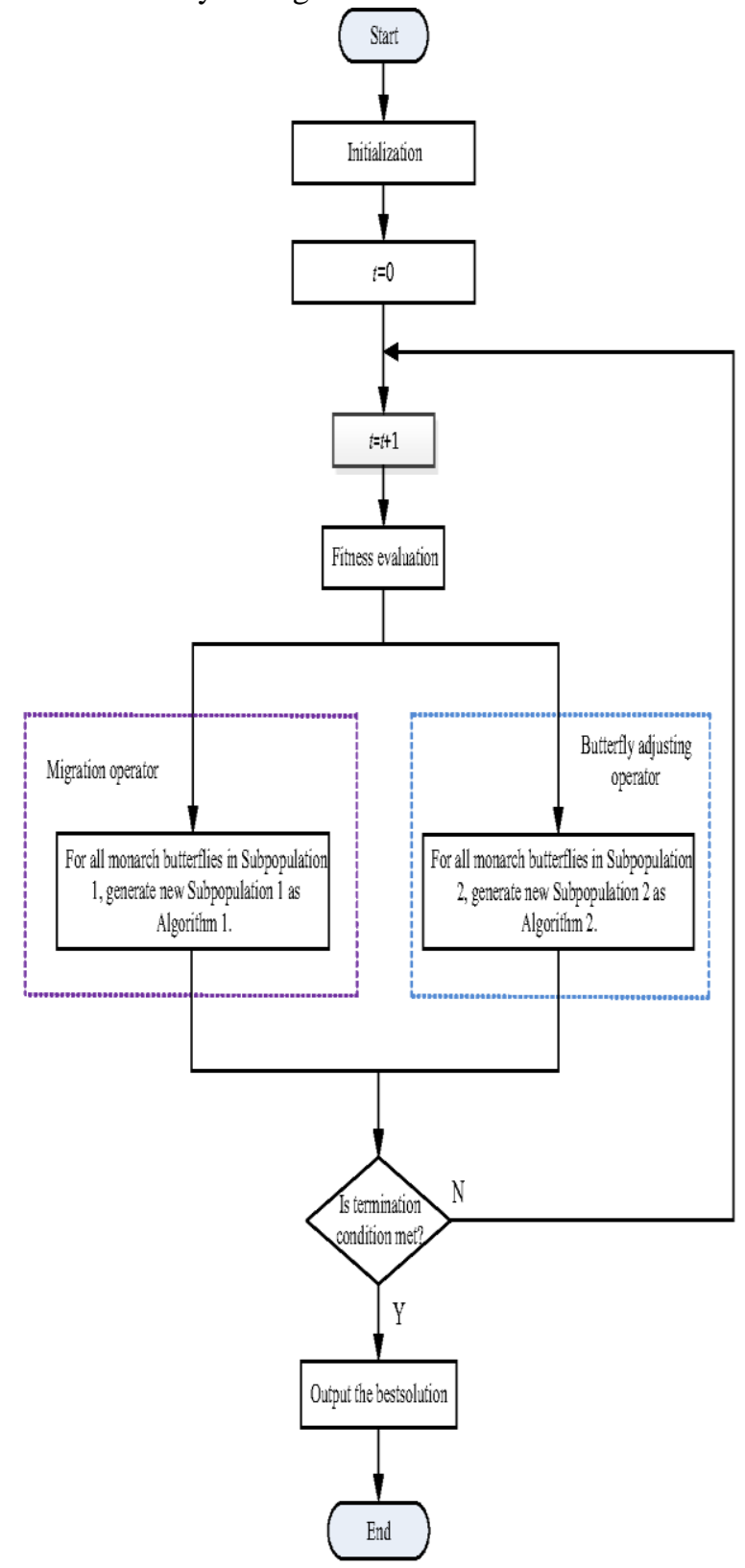

Fig. 2. MBHS algorithm flowchart

$$
\begin{aligned}
& x_{r_{2} k}^{t}=x_{r_{2} k}^{t}+\left(\max \left(H M_{r_{2} k}\right)-x_{r_{2} k}^{f}\right) \times \operatorname{rand}[0,1) \\
& x_{r_{2} k}^{t}=x_{r_{2} k}^{t}+(22) \\
& \left.\quad x_{r_{2} k}^{f}-\max \left(H M_{r_{2}, k}\right)\right) \times \operatorname{rand}[0,1)
\end{aligned}
$$

The randomization rule means to include population decent variety, it causes HS to investigate the hunt space very productively, prompting increment the likelihood of finding the worldwide ideal arrangement. In this way, the randomization rule produces another incentive for the kth component in the individual I rx2.

$$
x_{i}=L B_{i}+r \times\left(U b_{i}-L b_{i}\right)
$$

Where $U b$ and $L b$ are the maximum and minimum bounded for xi correspondingly.

\section{B. Particle Swarm Optimization (PSO)}

PSO [25] based computation convinced by the segments and rising conduct which ascends to manage territories. PSO calculation misuses masses of people to test promising regions of the intriguing space. In this uncommon condition, the majority is called swarm and the all-inclusive community is called particles or directors.

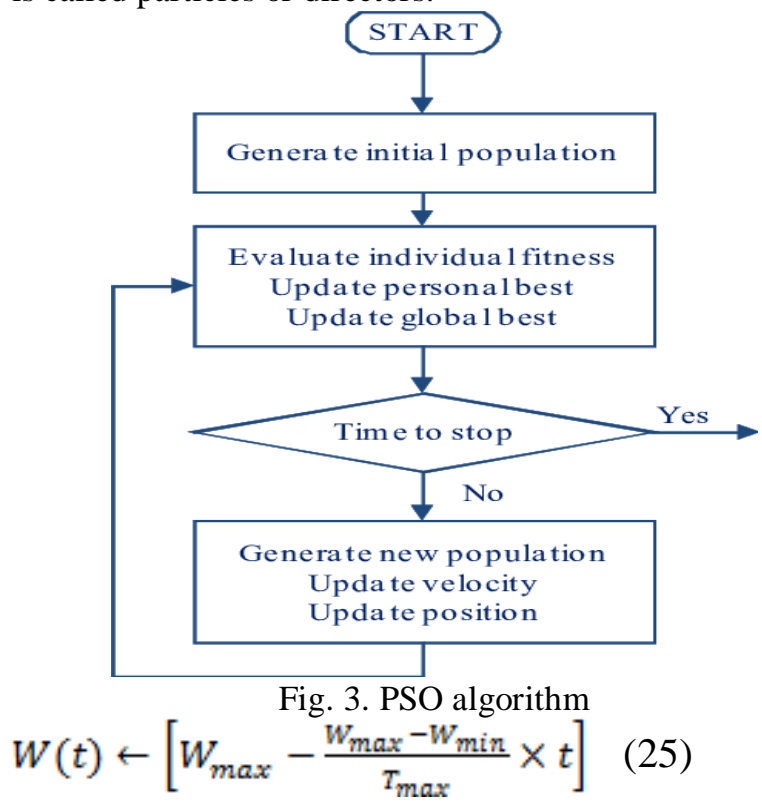

\section{Result AND Discussion}

\section{IEEE 30-bus test system}

In this area, the consequences of managing OPF issues by the execution of LTLBO calculation, gotten by increase runs will be displayed. So as to study the execution and nature of the proposed LTLBO calculation subject to Newton physical law [6] of gravity and law of advancement which is tried standard IEEE 30-transport test structure has appeared in Fig. 4.

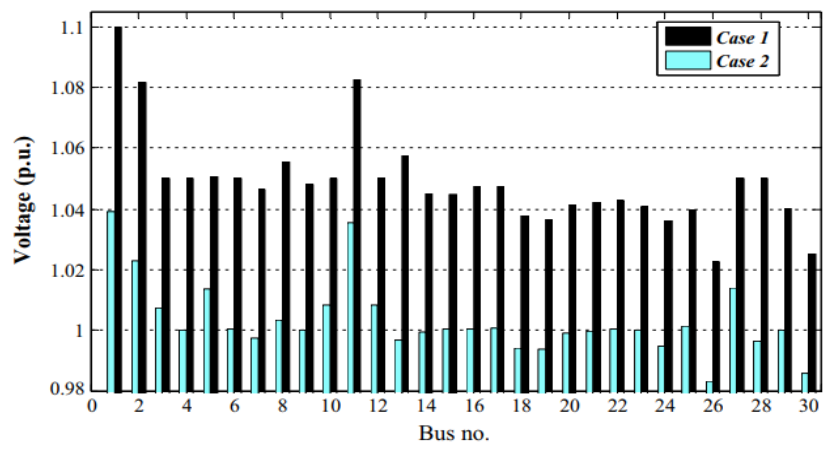

Fig. 4. Voltage variations for buses

Table- I: Simulation comparison results for the proposed model in IEEE 30 bus system. 
Hybrid algorithm based on MBHS and PSO with Optimal Power Flow Problem for Non-Smooth Cost Functions

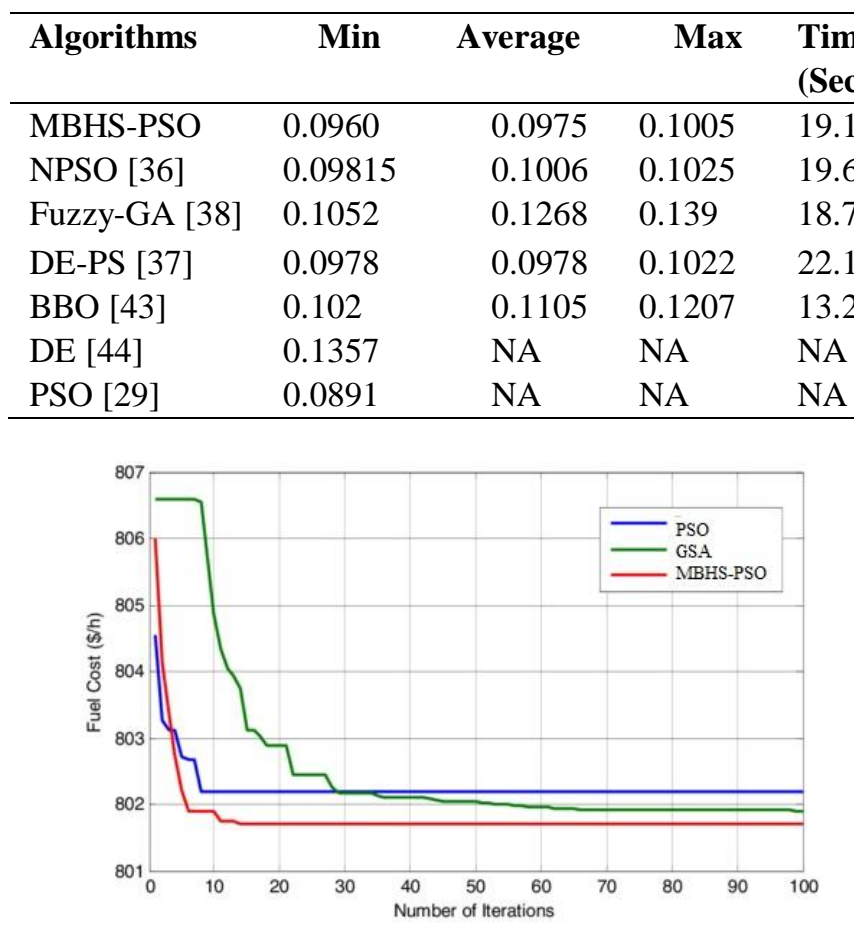

Fig. 5. Simulation comparison results for the proposed model in IEEE 30 bus system.

\section{IEEE 57-bus test system}

So as to study the adequacy and execution of LTLBO include in more prominent scale control frameworks, a standard IEEE 57-transport test structure is displayed as the showing ground for stage 2 of the reenactments.

Table- II: Simulation comparison results for the proposed model in IEEE 57 bus system.

\begin{tabular}{lc}
\hline Algorithms & Fuel Cost(\$/h) \\
\hline MBHS-PSO & 41512.5451 \\
NPSO [36] & 41699.5163 \\
Fuzzy-GA [38] & 41716.2808 \\
DE-PS [37] & 41685.295 \\
ABC [40] & 41693.9589 \\
LDI-PSO [40] & 41815.5035 \\
GSA [40] & 52819.7052 \\
\hline
\end{tabular}

Table- III: Generator cost coefficient for model [33, 34].

\begin{tabular}{llll}
\hline Bus No. & $\boldsymbol{\alpha}$ & $\mathbf{b}$ & $\mathbf{c}$ \\
\hline 1 & 0.00 & 2.00 & 0.00325 \\
2 & 0.00 & 1.74 & 0.01730 \\
5 & 0.00 & 1.03 & 0.06240 \\
8 & 0.00 & 3.15 & 0.00821 \\
11 & 0.00 & 3.01 & 0.02501 \\
13 & 0.00 & 3.00 & 0.02516 \\
\hline
\end{tabular}

Table- IV: The limits of the control variable [26],

\begin{tabular}{|c|c|c|}
\hline Control variables & Min & Max \\
\hline PG1 (MW) & 50 & 200 \\
\hline PG2 (MW) & 20 & 80 \\
\hline
\end{tabular}

\begin{tabular}{|c|c|c|}
\hline PG5 (MW) & 15 & 50 \\
\hline PG8 (MW) & 10 & 35 \\
\hline PG11 (MW) & 10 & 30 \\
\hline PG13 (MW) & 12 & 40 \\
\hline V1 (p.u) & 0.95 & 1.1 \\
\hline V2 (p.u) & 0.95 & 1.1 \\
\hline V5 (p.u) & 0.95 & 1.1 \\
\hline V8 (p.u) & 0.95 & 1.1 \\
\hline V11 (p.u) & 0.95 & 1.1 \\
\hline V13 (p.u) & 0.95 & 1.1 \\
\hline T11 (p.u) & 0.90 & 1.1 \\
\hline T12 (p.u) & 0.90 & 1.1 \\
\hline T15 (p.u) & 0.90 & 1.1 \\
\hline T36 (p.u) & 0.90 & 1.1 \\
\hline QC10 (MVAR) & 0.00 & 5.0 \\
\hline QC12 (MVAR) & 0.00 & 5.0 \\
\hline QC15(MVAR) & 0.00 & 5.0 \\
\hline QC17 (MVAR) & 0.00 & 5.0 \\
\hline QC20 (MVAR) & 0.00 & 5.0 \\
\hline QC21 (MVAR) & 0.00 & 5.0 \\
\hline QC23 (MVAR) & 0.00 & 5.0 \\
\hline QC24 (MVAR) & 0.00 & 5.0 \\
\hline QC29 (MVAR) & 0.00 & 5.0 \\
\hline
\end{tabular}

The obtained best fuel cost from applying MBHS and PSO calculation is $41679.5451 \$ / \mathrm{h}$. By taking a gander at the results in all Table were presented in this paper, and taking everything in account, the best wind cost controlled by the proposed calculation is less interestingly with the uncovered best result the composition.

\section{Conclusion}

In this paper, hybrid of MBHS-PSO has been, sufficiently, finished to manage the OPF issue of power structure outfitted. This 
estimation has been OPF issue sorts of target limits, on changed IEEE 30-transport and IEEE 57-transport test sway framework. The outcomes got from the proposed MBHS-PSO approach are separated and those distinct in the advancing top level making. It has been seen that the MBHS-PSO can join to a pervasive quality approach and has inconceivable mixing properties separated and different frameworks beginning late detailed in the paper.

\section{ACKNOWLEDGMENT}

The authors thankfully acknowledge support from the administration, Kalasalingam Academy of Research And Education, Krishnankoil, India. The authors would like to thank the reviewers for their valuable time to review the paper and better enhancement in further.

\section{REFERENCES}

[1] Niknam T, Jabbari M, Malekpour AR. A modified shuffle frog leaping algorithm for multi-objective optimal power flow. Energy 2011;36:6420-32.

[2] Sayah S, Zehar K. Modified differential evolution algorithm for optimal power flow with non-smooth cost functions. Energy Convers Manage 008;49: 3036-42.

[3] Ghasemi M, Ghavidel S, Ghanbarian MM, Massrur HR, Gharibzadeh M Application of imperialist competitive algorithm with its modified techniques for multi-objective optimal power flow problem: a comparative study. Inform Sci 2014.

[4] Gitizadeh M, Ghavidel S. Improving transient stability with multi-objective allocation and parameter setting of SVC in a multi-machine power system. IETE J Res 2014;60:33-41.

[5] Abido M. Optimal power flow using tabu search algorithm. Electric Power ComponenSyst 2002;30:469-83.

[6] Devaraj D, Yegnanarayana B. Genetic-algorithm-based optimal power flow for security enhancement. IEE Proc-Generat, TransmDistribut 2005;152: 899-905.

[7] Lai LL, Ma J, Yokoyama R, Zhao M. Improved genetic algorithms for optimal power flow under both normal and contingent operation states. Int J Electric Power Energy Syst 1997;19:287-92.

[8] Bakirtzis AG, Biskas PN, Zoumas CE, Petridis V. Optimal power flow by enhanced genetic algorithm. Power Syst, IEEE Trans 2002;17:229-36.

[9] Varadarajan M, Swarup K. Solving multi-objective optimal power flow using differential evolution. Generat, TransmDistrib, IET 2008;2:720-30.

[10] Roa-Sepulveda C, Pavez-Lazo B. A solution to the optimal power flow using simulated annealing. Int $\mathrm{J}$ Electri Power Energy Syst 2003;25:47-57.

[11] Somasundaram P, Kuppusamy K, Kumudini Devi R. Evolutionary programming based security constrained optimal power flow. Electric Power Syst Res 2004;72:137-45.

[12] Zimmerman R, Carlos E, Gan D. MATPOWER: A MATLAB Power System Simulation Package, Version 3.1 b2, User's Manual. Power Systems Engineering Research Center, Tech Rep; 2006.

[13] Milano F. An open source power system analysis toolbox. Power Syst, IEEE Trans 2005;20:1199-206.

[14] Ongsakul W, Bhasaputra P. Optimal power flow with FACTS devices by hybrid TS/SA approach. Int $\mathbf{J}$ Electr Power Energy Syst 2002;24(10):851-7.

[15] Basu M. Multi-objective optimal power flow with FACTS devices. Energy Convers Manage 2011;52(2):903-10.

[16] Basu M. Optimal power flow with FACTS devices using differential evolution. Int J Electr Power Energy Syst 2008;30(2):150-6.

[17] Chung TS, Li YK. A hybrid GA approach for OPF with consideration of FACTS devices. IEEE Power Eng Rev 2000;20(8):54-7.

[18] Belkacem M, Bouktir T, Srairi K, Benbouzid L. Dynamic strategy based fast decomposed GA coordinated with FACTS devices to enhance the optimal power flow. Energy Convers Manage 2010;51(7):1370-80.

[18] Kennedy J, Eberhart R. Particle swarm optimization. In: IEEE intconf neural networks, vol. 4; 1995. p. 1942-8.

[19] Valle YD, Venayagamoorthy GK, Mohagheghi S, Hernandez J, Harley RG. Particle swarm optimization: basic concepts, variants and applications in power systems. IEEE Trans EvolComput 2008;12(2):171-95.
[20] AlRashidi MR, El-Hawary ME. A survey of particle swarm optimization applications in electric power systems. IEEE Trans EvolComput 2009;13(4):913-8.

[21] Clerc M, Kennedy J. The particle swarm - explosion, stability, and convergence in a multidimensional complex space. IEEE Trans EvolComput 2002;6(1):58-73.

[22] B. Stott, O. Alsac, and A.J. Monticelli, "Security Analysis and Optimization," Proceedings of the IEEE, vol. 75, no. 12, pp. 1623-1644, 1987.

[23] Y. Tao and A.P.S. Meliopoulous , "Optimal Power Flow via Quadratic Power Flow," IEEE Power Systems Conference and Exposition, Phoenix, May 2011.

[24] W.F. Tinney, J.M. Bright, K.D. Demaree, B.A. Hughes, "Some Deficiencies in Optimal Power Flow," IEEE Transactions on Power Systems, Vol. 3 No. 2, pp. 676-683, May 1988.

[25] W.F. Tinney, "A presentation to the workshop in engineering mathematics and computer sciences," EPRI publication EAR/EL-7/07, pages 1-15, August 1991.

[26] W.-M. Lin, C.-H. Huang, T.-S. Zhan, “A Hubrid Current-Power Optimal Power Flow Technique,” IEEE Transactions on Power Systems, Vol. 23 No. 1, p. 177, Feb. 2008.

[27] J.B. Ward and H.W. Hale, "Digital Computer Solution of Power Flow Problems," Trans. AIEE (Power Apparatus and Systems), vol. 75, pp. 398-404, Jun. 1956.

[28] R.B. Squires, "Economic Dispatch of Generation Directly from Power System Voltages and Admittances," AIEE Trans. vol. 79, pt. III, pp. 1235-1244, 1961.

\section{AUTHORS PROFILE}

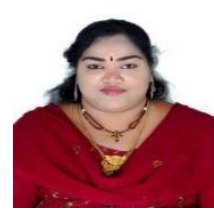

Dr.C.SHILAJA is a Research Faculty in Department of Electrical and Electronics Engineering in Kalasalingam Academy of Research and Education. Now currently pursuing Post-Doctoral Fellowship from Kalasalingam Academy of Research and Education.in 2018, received her Ph.D. in Power System Electrical \& Electronics Engineering from VIT University Vellore in 2018, her M.E. in Power Electronics \& Industrial Drives from Sathyabama University in 2010 and her MBA in Human Resources from Alagappa University karaikudi in 2007. Then her B.E. in Electrical and Electronics Engineering from Madras University in 2003. Her Research interests include Power system optimization, Renewable Energy, Optimal scheduling \& Power system planning. She has published 18 International journals and 4 International conferences in these area. 